\title{
EDITORIAL
}

\section{State of the Journal: 2011}

\section{Journal of Perinatology (2011) 31, 225-227; doi:10.1038/jp.2011.9}

Over the past several years, I have written annually to update the readership regarding changes in the Journal of Perinatology. This brief forum is also used to thank our outstanding external, independent reviewers for their anonymous yet significant contributions to ensuring the journal's continuing excellence. This year, as in the past, I will mention several important developments to the journal, such as new associate editors, changes to the Editorial Board, continuing growth of the Journal of Perinatology with regard to manuscript submissions and the recent Thomson Reuters Impact Factor assignments. The Journal of Perinatology website has been adding new and informative features that deserve mention. I have also appended a list of last year's fine reviewers in an effort to individually thank them for their otherwise unrecognized work to improve the Journal of Perinatology.

Last year we added two new associate editors to aid in the evaluation of manuscripts on neonatal medicine. This year, the continuing growth of our international submissions has mandated the appointment of an additional International Section Editor: Arun K Pramanik, Chief of Neonatology at Louisiana State University, Shreveport, LA, USA. He will share these responsibilities with Arthur Eidelman, who has for the last 5 years been the sole International Section Editor. Dr Gordon, Dr Bhatia and Dr Caughey continue in their roles as associate editors of the Neonatal, Supplements and Maternal-Fetal Medicine sections. All the editors review initial submissions, determine initial priority for publication and decide whether to continue evaluating a manuscript for eventual publication. The editors then assign reviewers and receive and evaluate the reviews and advise authors on decisions regarding necessary manuscript edits and the final decisions.

I thank our many members of the diverse Editorial Board who provide their expertise and leadership in support of the Journal of Perinatology and contribute to its development in many ways, including advice on new areas of interest. The members of the Editorial Board are frequently called upon to referee articles that may be outside the purview of their personal expertise. Two Board members, Malcome Levene and Hugo Lagercrantz have retired. We will miss their leadership on the Board, but I intend to continue using their services in a reduced manner as reviewers of select manuscripts that are directly relevant to their respective fields of research. Krishnamurthy C Sekar, MD, Professor of Pediatrics and Medical Director of the neonatal intensive care unit at the
University of Oklahoma Health Sciences Center, is our new Board member, who joined the Board in 2011.

The Journal has been indexed by major electronic abstracting services for many years. In addition, a select group of journals are assigned an Impact Factor by the Thomson Reuters Company on an annual basis. The Impact Factor is an index relating to the number of citations to the published articles in a specific journal over the preceding 2-year period. In 2009 and 2010, the Journal was assigned its first Impact Factors - 1.621 from 2007 to 2008 and 1.593 for articles published in years from 2008 to 2009. Both rankings place the Journal in the upper half of all pediatric journals rated by Thomson Reuters. The Impact Factor is used by some individuals and organizations as a means to assess the importance of a journal, although it should only be used with the knowledge of the various factors that limit the score's meaningfulness. For us, the consistency of these two scores represents acceptance of the scientific reliability of the Journal by our broader audience of scholars and clinicians. Another indication of acceptance by the scientific community is the rising number of submitted manuscripts. In 2010, we received over 700 new manuscripts, representing a $22 \%$ increase over the number received in 2009 .

Nature Publishing Group has provided excellent tools to assist the authors, editors, reviewers and readers. The Manuscript Tracking System allows electronic submission of completed manuscripts and tracks manuscripts through the review process, allowing authors and staff to follow the manuscripts through the various review stages. Also supporting the publication process is the Advanced Online Publication, where accepted manuscripts (Original Articles and State of Art Reviews) are published electronically within weeks of receipt of galley proofs, providing rapid, timely publication. These articles are considered published as of the electronic date and are indexed on the various electronic search engines through which interested readers may learn of their publication. The Journal of Perinatology website (http:// www.nature.com/jp/index.html) shows the current issue and identifies featured articles that are available as free downloads. In addition, other components of the website include references to select other Nature Publishing Group-relevant articles, a calendar of meetings relevant to our field, archives of the Journal's issues and identification of relevant articles in the Journal Supplement issues.

Over the course of the coming year, the editors and referees will continue to select high-quality original articles, clinical 
case presentations and research reviews that embrace the multidisciplinary scope of the Maternal-Fetal Medicine and Neonatal-Perinatal specialties. We aim to provide an interesting,

\section{Reviewers list}

Kjersti Marie Aagaard

David H Adamkin

Vincent Adolph

Henry Akinbi

Heidelise Als

Hany Z Aly

Shin Amamiya

Paula Amato

Namasivayam Ambalavanan

Sanjiv B Amin

Harry Applebaum

Ronald Lee Ariagno

Shmuel Arnon

Terri Ashmeade

Joshua Attridge

Henrietta Bada

Jennifer Bailit

Keith J Barrington

Bruce Barshop

Stephen Baumgart

Alan Bedrick

Graeme Bell

Catherine M Bendel

Kurt Benirschke

William E Benitz

Danny Benjamin

Itai Berger

Scott David Berns

Carol Lynn Berseth

Vineet Bhandari

Jatinder Bhatia

Vinod K Bhutani

Alona Bin Nun

Howard J Birenbaum

David Birnkrant

Mary Thiery Blackwell

Barry T Bloom

Yair Josh Blumenfeld

Renee Boss

Debra Brandon

Mary Brandt

Luc P Brion

Ruben Bromiker

Robert Brouillette

Mark Stuart Brown

Joy Browne

Beverly Brozanski

Elchanan Bruckheimer

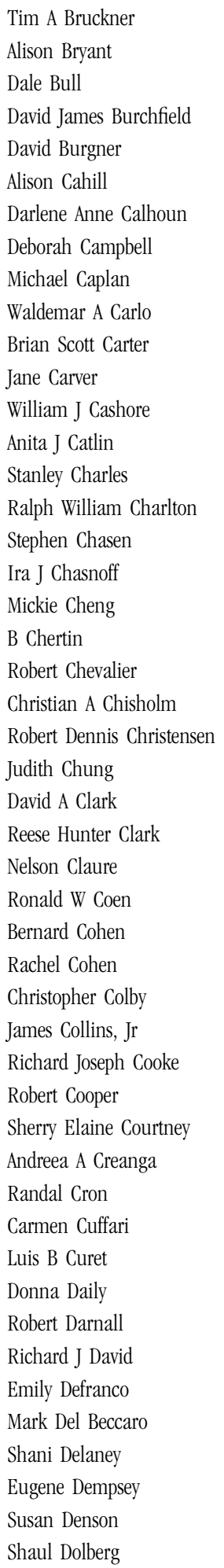

and occasionally provocative, reading experience that improves the clinical practice of our readers. As always, suggestions to enhance our worth to you will always be enthusiastically received.

\begin{tabular}{|c|c|}
\hline Steven M Donn & David Hackney \\
\hline Pamela K Donohue & Donna R Halloran \\
\hline Mia W Doron & Thor Hansen \\
\hline Antonette T Dulay & Thomas Hegyi \\
\hline Manuel Durand & Jonathan Hellmann \\
\hline Eric Eichenwald & Ann Hellstrom \\
\hline Yasser Yehia El-Sayed & Victor Herson \\
\hline Samir Eldahr & Rosemary Dowe Higgins \\
\hline Michal Elovitz & Pamela Hill \\
\hline William A Engle & Harry Hirsch \\
\hline William D Engle & David J Hoffman \\
\hline Cyril Engmann & Diane Holditch-Davis \\
\hline Juan-Sanchez Esteban & Ian Holzman \\
\hline Nick Evans & C Howard \\
\hline Jonathan Fanaroff & Udo Hoyme \\
\hline Tanis Fenton & Mark L Hudak \\
\hline Neil N Finer & Thomas Hulsey \\
\hline David Flannery & Michael T Hynan \\
\hline Magali Jacqueline Fontaine & Rebecca N Ichord \\
\hline Norman Fost & Jessica Illuzzi \\
\hline Lynda Frassetto & Saleem Islam \\
\hline Antonio Frias & Oussama Itani \\
\hline Alan M Fujii & Lucky Jain \\
\hline Ed Funai & Sushil K Jain \\
\hline Lydia Furman & Vanitha Janakiraman \\
\hline Matthew J Garabedian & Douglas Jones \\
\hline Mark Gaylord & Sandra E Juul \\
\hline Ira Gewolb & Anjali J Kaimal \\
\hline William M Gilbert & Jeffrey R Kaiser \\
\hline Martin Gimovsky & Deborah Kamali \\
\hline Penny Glass & Julie Kanter \\
\hline Christina Glick & Michael Kaplan \\
\hline Ronald N Goldberg & Zenichiro Kato \\
\hline Jay Goldsmith & David Kaufman \\
\hline Ricki Goldstein & Ajay Kaul \\
\hline Sergio G Golombek & William Keenan \\
\hline Victor H Gonzalez-Quintero & Carole Kenner \\
\hline Phillip V Gordon & Jacqueline Kent \\
\hline Ernest Graham & Martin Keszler \\
\hline Anne Greenough & Howard W Kilbride \\
\hline Jay S Greenspan & Jae Kim \\
\hline Ian Griffin & Kwang Sik Kim \\
\hline Sorina Grisaru-Granovsky & Lena Kim \\
\hline William Grobman & $\mathrm{T}$ Kiserud \\
\hline Alan Groves & Panagiota Kitsantas \\
\hline Edith Gurewitsch & Peter Klatsky \\
\hline Stephen 0 Gyimah & Pamela Jean Kling \\
\hline Maureen Hack & Martin Kluckow \\
\hline
\end{tabular}


Alex Knisely

Robert Koppel

Takuji Kouzuma

Christopher Kovacs

Amir Kugelman

Juan Pedro Kusanovic

Mike Kuzniewicz

Alain Labrique

David Lagrew

Mark Landon

Abbot R Laptook

Janet Larson

Matthew Laughon

Adrian Lavery

Edward E Lawson

Kathryn Lee

Men-Jean Lee

Maureen Lefton-Greif

Christoph Ulrich Lehmann

Jocelyn Amy Lewis

John Wells Logan

Scott Andrew Lorch

M Jeffrey Maisels

Imad R Makhoul

Michael Howard Malloy

Mark C Mammel

Kyla Anna Marks

Diane D Marshall

Gilbert I Martin

Oommen Mathew

Katherine R McCallie

Jane E McGowan

Sharon A McGrath

William Meadow

Orly Meged

T Allen Merritt

Andrew Meyer

Marlene Miller

J Ross Milley

Kenneth Moise

James Moore

Karen H Morin

Fernando Moya

Luke Charles Mullany

Jonathan Muraskas

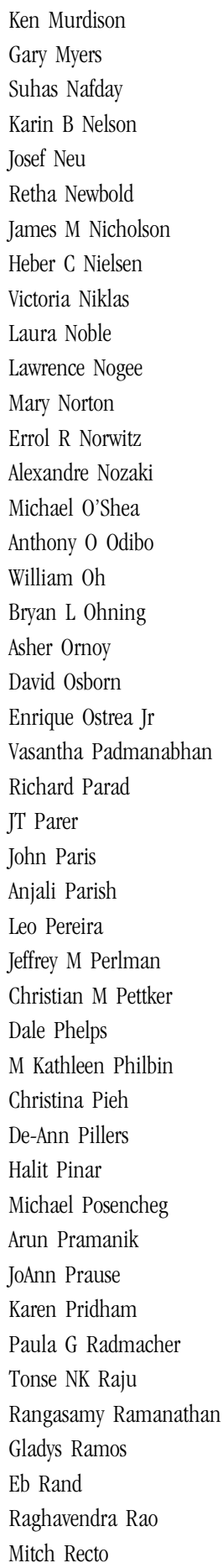

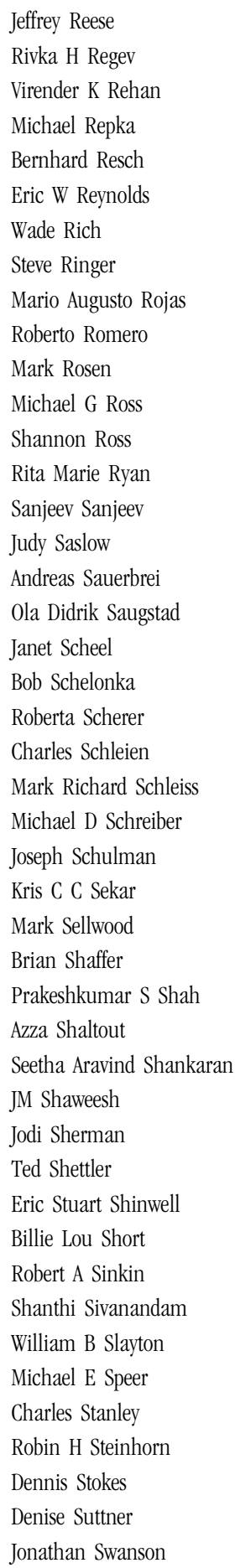

Robert Glenn Tefft

Aylin Tekes

Mishka Terplan

Marianne Thoresen

Suzanne Thoyre

Stephen Thung

Patti J Thureen

David Tingay

Alan T N Tita

Jorge Tolosa

Philip Toltzis

William E Truog

Dan Turner

Atsushi Uchiyama

Martin H Ulshen

Adam Urato

Robert L Ursprung

Dharmapuri Vidyasagar

Marty Visscher

Betty Vohr

Carol L Wagner

Michele C Walsh

William F Walsh

Frans J Walther

David Warburton

William J Watson

Stephen E Welty

Bjorn Westrup

Susan E Wiedmeier

Nancy Wight

Dominic James Wilkinson

David D Wirtschafter

Thomas E Wiswell

Ian Michael Wright

Danny Wu

Solange Wyatt

Toby Debra Yanowitz

Tom Yeh

Bradley A Yoder

Christina Yoshinaga-Itano

Thomas E Young

Santina Agnes Zanelli

Ekhard Ziegler

\section{Conflict of interest}

The author declares no conflict of interest.

EE Lawson Editor-in-Chief Department of Pediatrics, Division of Neonatology, Johns Hopkins Medical Institutions, Baltimore, MD, USA E-mail: elawson1@jbmi.edu 